\title{
Danzando en la diversidad: reflexiones sobre la inclusión y pertinencia de la diversidad en la educación dancística y artística ${ }^{1}$
}

\author{
Caballero Segura Carolina ${ }^{2}$ \\ Instituto Universitario de la Paz, Unipaz, Barrancabermeja, Colombia ${ }^{3}$ \\ fionacaba@gmail.com
}

1 Artículo de investigación resultado de una indagación de carácter cualitativo y descriptivo, que se basa en el trabajo que fomenta la organización ConCuerpos en Colombia al convocar a personas con y sin discapacidad a través de la danza, para promover una cultura inclusiva.

2 Psicóloga de la Universidad Javeriana de Bogotá (2007), titulada en danza con la Maestría de Artes Finas (M.F.A) en danza de la Universidad de Oregón, E.U. (2013). Es cofundadora de ConCuerpos, corporación que incluye personas con y sin discapacidad a través de la danza contemporánea. Se desempeñó como codirectora de la organización desde sus inicios, 2007 hasta el 2015.

3 Docente e investigadora de la Licenciatura de Artes, en el área de Danza 


\title{
Danzando en la diversidad: reflexiones sobre la inclusión y pertinencia de la diversidad en la educación dancística y artística
}

\section{Resumen}

El artículo plantea algunas reflexiones en torno a la danza contemporánea inclusiva y busca articular la investigación académica con la experiencia artística y pedagógica que se fomenta en Colombia a partir de la danza inclusiva. La investigación se basa en el trabajo que fomenta la organización ConCuerpos en Colombia al convocar a personas con y sin discapacidad a través de la danza, para promover una cultura inclusiva. Se propone que la danza inclusiva ofrece espacios para la comprensión y afirmación del cuerpo en su diversidad. Al considerarse la danza contemporánea una práctica que plantea una pedagogía para el cuerpo, el fomento de la creatividad y el trabajo colectivo, se sostiene que el reconocimiento, la valoración y el respeto por la diferencia de las personas en una práctica inclusiva son herramientas claves para el quehacer del estudiante de Licenciatura en Artes. La reflexión pretende dar cuenta de las posibilidades que ofrece la danza contemporánea al reto de la inclusión e iniciar la discusión sobre dicha temática en los espacios académicos de formación pedagógica en danza.

En un programa de Licenciatura en Artes, donde la danza hace parte importante de sus contenidos, el reto de la inclusión se hace una realidad apremiante a ser digerida y elaborada por los futuros docentes y profesionales. Como valor agregado, el artículo espera aportar a la comprensión de la sociedad como entramados complejos de relaciones en los que la discusión sobre la inclusión abre posibilidades para crear tejidos más humanos y participativos a través de la danza y el arte en general.

Palabras clave: Danza contemporánea inclusiva, cuerpo, pedagogía, didácticas de la danza, discapacidad.

\section{Dancing in the diversity: reflections about the inclusion and pertinence of the diversity in the artistic and dancingeducation}

\begin{abstract}
This article, as the result of a qualitative and descriptive inquiry, raises some reflections on inclusive contemporary dance. The brief seeks to articulate academic research to the artistic and pedagogical experience that is encouraged in this field in Colombia. Specifically, the investigation focus on the work of ConCuerpos, an organization that brings together people with and without disabilities, through dance and promotes an inclusive dance culture. Thus it is proposed that the inclusive contemporary dance offers an understanding and affirmation of the body in its diversity. When considering contemporary dance as a practice that poses a pedagogy for the body, promoting creativity and collective work, it is argued that recognition, appreciation and respect for differences among people are key tools to the student to do a Bachelor of Arts.In this sense, the reflection seeks to explain the possibilities offered by contemporary dance to the challenge of inclusion, and initiate a discussion on this topic in academic areas of teacher training in dance.

In a Bachelor of Arts, where dance becomes an important part of its contents, the challenge of inclusion is paramount to be understood and elaborated by future teachers. As an added bonus, the article hopes to contribute to the understanding of society as complex network of relationships in which the discussion on the inclusion opens up possibilities to create more human and participatory societies through dance and art in general.
\end{abstract}

Keywords: Inclusive contemporary dance, body, pedagogy, teaching dance, disability, disability studies.

\section{Dançando na diversidade: reflexões sobre a inclusão e pertinência da diversidade na educação dancística e artística}

\section{Resumo}

O artigo propõe algumas reflexões em torno à dança contemporânea inclusiva e procura articular a investigação académica com a experiência artística e pedagógica que se fomenta em Colômbia a partir da dança inclusiva. A investigação baseia-se no trabalho que fomenta a organização ConCuerpos na Colômbia ao convocar a pessoas com e sem discapacidade através da dança, para promover uma cultura inclusiva. Propõe-se que a dança inclusiva oferece espaços para o entendimento e afirmação do corpo em sua diversidade. Ao considerar-se dança-a contemporânea uma prática que propõe uma pedagogia para o corpo, a alavancagem da criatividade e o trabalho coletivo, se sustenta que o reconhecimento, a valoração e o respeito pela diferença das pessoas numa 
prática inclusiva são ferramentas essenciais para o quehacer do estudante de Licenciatura em Artes. A reflexão pretende dar conta das possibilidades que oferece a dança contemporânea ao desafio da inclusão e iniciar a discussão sobre dita temática nos espaços académicos de formação pedagógica em dança.

Num programa de Licenciatura em Artes, onde a dança faz parte importante de seus conteúdos, o repto da inclusão se faz uma realidade apremiante a ser digerida e elaborada pelos futuros docentes e profissionais. Como valor agregado, o artigo espera contribuir ao entendimento da sociedade como malhas complexas de relações nos que a discussão sobre a inclusão abre possibilidades para criar tecidos mais humanos e participativos através da dança e a arte em general.

Palavras-chave: dança inclusiva contemporânea, corpo, pedagogia, ensino da dança, deficiência. 


\section{Introducción}

La danza contemporánea inclusiva en Colombia es una práctica relativamente reciente y novedosa. Sin embargo, desde sus inicios en el 2007 ha tenido gran aceptación y reconocimiento, siendo parte tanto de proyectos de investigación académica, como de la escena artística de la danza contemporánea del país.

Su acogida se ha dado, en gran parte, a que después de realizarse el primer taller de danza inclusiva en Bogotá, que reunió diversas personas de diferentes regiones del país, se forma el grupo ConCuerpos. Este grupo se consolida con la intención de abrir un nuevo campo de exploración e investigación artística en el país de carácter inclusivo, convocando personas con y sin discapacidad a danzar juntas. Gracias a su estructura, es posible realizar Cuerpos IndiVisibles en Movimiento: Danza Contemporánea como Espacio de Inclusión Social, un proyecto de investigación avalado por El Departamento Administrativo de Ciencia, Tecnología e Innovación (Colciencias), dentro del programa de becas para Jóvenes Investigadores e Innovadores 2008 (Caballero, 2008).

El proyecto contribuyó a conocer los efectos subjetivos que los primeros talleres de danza inclusiva que se realizaron en el país tuvieron en los participantes. Esto fue clave para visualizar y sentar los principios generales dentro de los cuales se inscribe la práctica, así como para trazar un camino a seguir según el potencial que tenía el encuentro de personas diversas, a través de la danza.

En el 2009, ConCuerpos se constituye legalmente en una corporación sin ánimo de lucro, lo cual le da una mayor capacidad de acción para realizar sus iniciativas. La organización, preguntándose por las implicaciones pedagógicas, sociales, políticas y artísticas de la práctica, con el apoyo de instituciones como el British Coucil, el Ministerio de Cultura e IDARTES, pone a andar múltiples actividades; entre ellas, una clase permanente de danza inclusiva, talleres de formador a formadores y una compañía de danza profesional (Penagos, 2014).

ConCuerpos, como compañía profesional de danza inclusiva, ha tenido la posibilidad de presentarse tanto en escenarios nacionales como internacionales y hoy en día hace parte de la primera red de Danza e Integración Latinoamericana, que se conformó en septiembre de 2015 en Argentina, Buenos Aires (Ochoa, 2016).

Otro factor influyente para su acogida ha sido que en el Plan Nacional de Danza para un País que Baila 2010-2020 del Ministerio de Cultura, se reconoce a la danza 
Danzando en la diversidad: reflexiones sobre la inclusión y pertinencia de la diversidad en la educación dancística y artística

integrada ${ }^{4}$ como parte de las diferentes expresiones dancísticas del país (p.15). Este hecho asegura un espacio y recursos para su expansión. Por ejemplo, hoy por hoy existe también Inclusive Movimiento, otra organización sin ánimo de lucro que desarrolla actividades pedagógicas entorno al arte, el cuerpo y la inclusión.

Esta organización lo hace no sólo desde la danza contemporánea, sino desde el diseño y otras artes escénicas, reivindicando las diferentes formas de expresión y maneras en que conocen las personas, sin importar su condición física, intelectual o sensorial. A través de ésta se realiza en la ciudad de Bogotá el Diplomado Arte, Cuerpo e Inclusión, junto con el I y II Encuentro, que llevan el mismo nombre. Estos encuentros dieron la base para realizar más adelante el III Encuentro, que con el apoyo de IDARTES, propició el encuentro e intercambio de saberes entre organizaciones en el 2014. Gracias a Inclusive Movimiento, también fue posible la certificación de 24 maestros en Colombia en el método DanceAbility, impartido por su mismo fundador ${ }^{5}$ quien lleva más de 25 años trabajando en el campo.

Ahora bien, ¿qué es exactamente la danza contemporánea inclusiva? ¿A qué desarrollos responde y cuál ha sido el alcance de esta práctica?, más importante aún, ¿cuáles son sus posibles repercusiones para la pedagogía de la danza en el contexto colombiano? Éstas son algunas de las preguntas que el presente artículo intenta responder apelando a la investigación académica mencionada (2008) y al recorrido que han trazado las organizaciones desde el 2010, momento en el que se incluye a la danza inclusiva dentro del Plan Nacional de Danza. Es importante aclarar que el texto busca dar una idea general de los desarrollos de la danza inclusiva y así fomentar la discusión dentro del ámbito educativo de la danza, poniendo en diálogo nociones de cuerpo, discapacidad, movimiento, inclusión y subjetividad. La bibliografía responde a diferentes áreas de conocimiento que en su intersección fundamentan la práctica.

\section{Métodos y materiales}

Este artículo se enmarca dentro de los Estudios sobre Discapacidad, un campo interdisciplinario que estudia la discapacidad, su significado, naturaleza y repercusiones como un constructo social, reivindicando la subjetividad misma de las personas con discapacidad. El texto busca articular la primera investigación realizada en el Instituto Pensar de la Javeriana, avalada por Colciencias, Cuerpos IndiVisibles (2008) con la posterior trayectoria que ha tenido ConCuerpos, desarrollándose a nivel pedagógico y artístico.

4 La misma que se ha denominado hasta aquí inclusiva. Más adelante y sobre la cuál se explicará por qué el cambio de nominación.

5 Se hace referencia a Alito Alessi, con base en Estados Unidos, Eugene, Oregón, quien trabaja local, nacional e internacionalmente (recuperado el 1 de Marzo de 2016 de: http://inclusivemovimiento. weebly.com). 
Como marco teórico de esta indagación de tipo cualitativo se revisan nociones de danza contemporánea, educación y pedagogía inclusiva, discapacidad, cuerpo y subjetividad, para fundamentar la práctica de la danza contemporánea inclusiva en el contexto colombiano. Como metodología se combinan diferentes miradas de las ciencias sociales con aproximaciones novedosas como la fenomenología y los estudios etnográficos de cuerpo. Estos últimos traen la experiencia del investigador y sus participantes al centro de su producción de conocimiento, articulando teoría y práctica; además, actuando en coherencia con la naturaleza misma de la danza, en la que se considera al cuerpo una entidad sensible y perceptible, que se transforma con su práctica (Citro, 2012).

Como herramienta se utiliza la observación participativa, en la que la acción del investigador va "más allá" de ver (Siampieri, et al., 2010, pp. 411-412) y su rol es activo, involucrándose en las actividades, pasando en su análisis por fases de contrastes analíticos. Por ejemplo: alejamiento-acercamiento, acercamientoparticipación, distanciamiento-observación y un movimiento final de síntesis (Citro, 2012, p. 49). De esta manera, el investigador como observador participante describe comunidades, explora ambientes, comprende procesos, identifica problemáticas y sugiere hipótesis (Siampieri, et al., 2010, p. 412).

También se usa la revisión del registro audiovisual de los talleres realizados por la organización ConCuerpos en sus inicios 2008-2010 ${ }^{6}$ y la experiencia de inmersión de la investigadora quien fue facilitadora, bailarina y coreógrafa de talleres y piezas de danza inclusiva durante los años 2008-2015, principalmente con ConCuerpos en Colombia y de manera independiente durante el desarrollo de su Maestría en la Universidad de Oregón 2010-2013.

Para el desarrollo del análisis se tiene como objetivo general identificar los efectos que la danza inclusiva produce en sujetos con y sin discapacidad, a través de talleres, clases permanentes y las producciones artísticas de la compañía. Asimismo, determinar la importancia pedagógica que la práctica tiene para el contexto colombiano. Como objetivos específicos están: i) definir los conceptos que fundamentan la práctica de la danza inclusiva, ii) ubicar los discursos de cuerpo y discapacidad que permean la práctica dancística y iii) discutir las implicaciones que el hacer danza inclusiva tiene para la pedagogía y el país.

6 Ver: https://www.youtube.com/user/ConCuerpos/videos 
Danzando en la diversidad: reflexiones sobre la inclusión y pertinencia de la diversidad en la educación dancística y artística | Carolina Caballero Segura |

\section{Experiencia pedagógica y artística como insumos para la investigación}

Como se mencionaba anteriormente, los insumos que apoyan esta investigación son principalmente diferentes experiencias de campo. Para una mejor comprensión se hace una descripción de tres etapas que caracterizan el desarrollo y evolución de la práctica según la experiencia de la autora y que, unida a la teoría, articulan la discusión sobre las preguntas de indagación, que la presente investigación plantea.

\section{Primera etapa: consolidación de la práctica, realización del proyecto de investigación Cuerpos en InDivisibles en Movimiento: danza inclusiva como espacio de inclusión social}

Esta primera etapa está caracterizada principalmente por la realización de tres talleres de danza inclusiva en diferentes ciudades de Colombia durante el 2008. En estos talleres, la investigadora se desempeña desde una perspectiva de observación participativa, en tanto que facilita, apoya, registra, entrevista y discute con los participantes, y otras dos facilitadoras, en el proceso de los talleres.

El primer taller se realiza en la ciudad de Cali, del 25 de marzo al 11 de abril. Allí se ofrece un espacio de formación de dos semanas, dedicando una última a la realización de un montaje coreográfico que tiene lugar el 3 de junio dentro de la programación del Festival Caliendanza.

El espacio pedagógico de formación del taller tuvo lugar en dos jornadas: una por la mañana y otra por la tarde, a la que asistieron 36 personas diversas. Principalmente participaron bailarines, actores de teatro, terapeutas ocupacionales, educadores especiales y 8 personas en condición de discapacidad motora, cognitiva, física, auditiva y visual; algunas de ellas también con alguna experiencia escénica. La diversidad del grupo puede verse en la siguiente imagen:

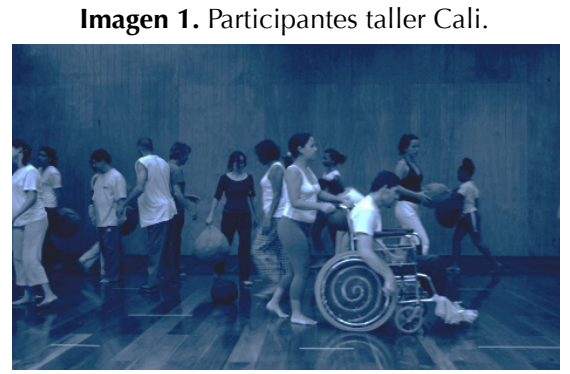

Fuente: Juan David Salazar 
El trabajo del taller en las primeras dos semanas estuvo enfocado a desarrollar la conciencia corporal, por medio de ejercicios tanto individuales (imagen 2.) como grupales, que permitieron el reconocimiento minucioso del cuerpo de cada participante, el contacto y la entrega de peso entre ellos (imagen 3). Así se logró una exploración de movimiento que permitió la creación de material, dispuesto, en la última semana, al montaje coreográfico.

Imagen 2: Exploración individual.

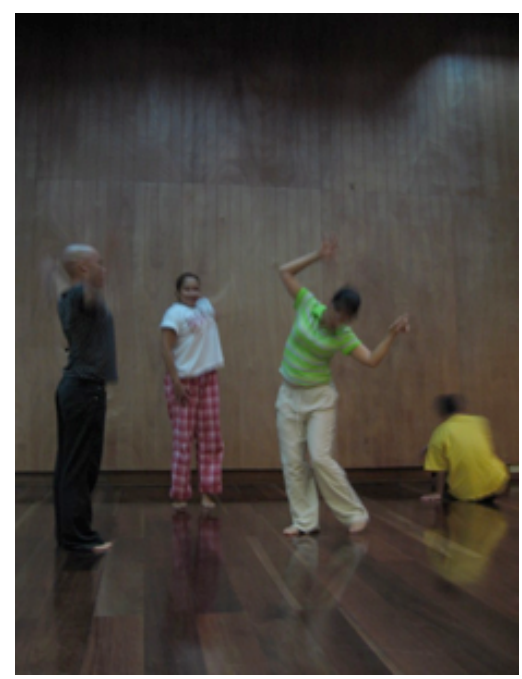

Fuente: Juan David Salazar

Imagen 3. Exploración grupal.

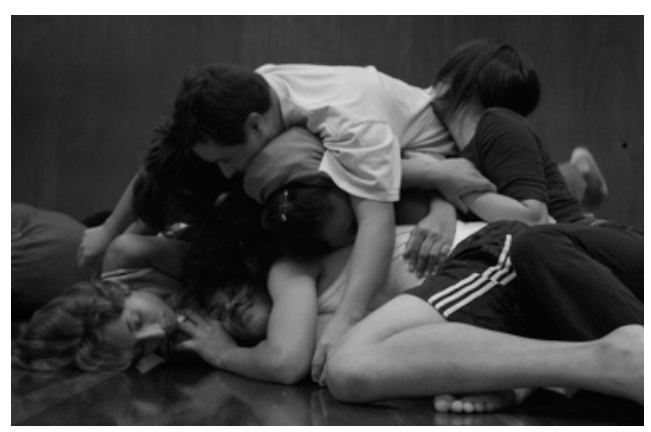

Fuente: Juan David Salazar

En la puesta en escena se combinó el movimiento, con objetos de escenografía: bolas rellenas a manera de almohadas de colores y diferentes tamaños, como puede 
Danzando en la diversidad: reflexiones sobre la inclusión y pertinencia de la diversidad en la educación dancística y artística | Carolina Caballero Segura |

verse en las imágenes 4 y 5 . Las bolas se manipularon individual y grupalmente, en duetos, pasándose por el grupo y lanzándose por el espacio.

Imagen 4. Material escenográfico.

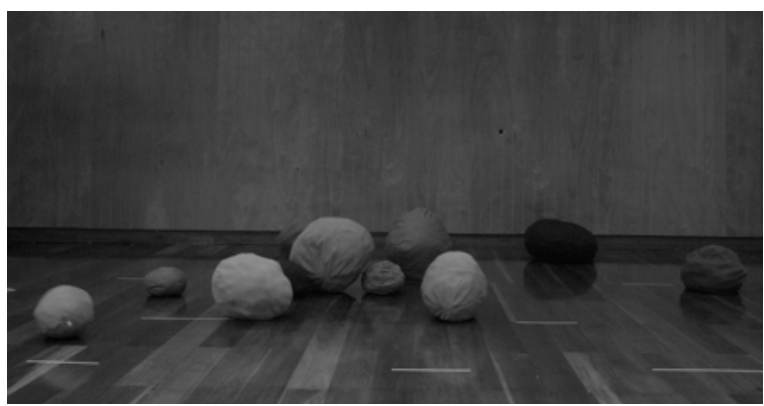

Fuente: Juan David Salazar

Imagen 5. Exploración con material escenográfico.

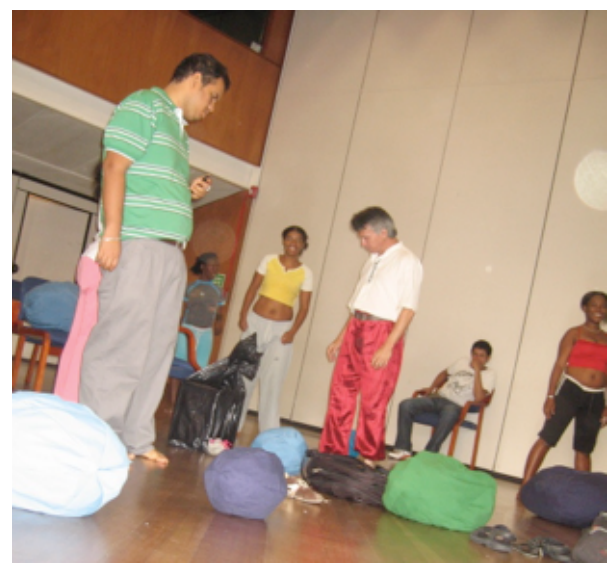

Fuente: Archivo Personal

El segundo taller tuvo lugar en la ciudad de Bogotá en el mes de agosto. Éste se realizó con la Fundación Arcángeles. Al taller asistieron 6 personas en total. Tres bailarines y tres personas con limitaciones motoras, una con discapacidad cognitiva; pero, ninguna de ellas con experiencia escénica.

El taller se llevó a cabo dos veces por semana por un periodo de un mes. Al final se hizo una socialización con una clase abierta. Los ejercicios también estuvieron dirigidos a la exploración y conocimiento personal y grupal. Se usaron los mismos principios exploratorios y expresivos del taller de Cali. 
El tercer taller se realizó en la ciudad de Sincelejo del 22 al 28 de septiembre. En el encuentro contamos con la participación de personas ya inmersas dentro del mundo de la danza y la música, con un trabajo previo del cuerpo y el movimiento, así como de profesores(as) y familiares acompañantes. Entre las discapacidades participaron dos personas con problemas de aprendizaje, una persona sorda, dos con síndrome de Down (entre ellos un joven que no fue muy constante) y una persona con parálisis motora.

Los ejercicios se dirigieron a una sensibilización del cuerpo propio y del otro, reconociendo el espacio como un lugar en el que se es posible establecer relaciones específicas con los otros, a través de diferentes dinámicas de movimiento. Las velocidades, las formas de desplazamiento, los niveles y el contacto, fueron elementos que se profundizaron.

Estos talleres tienen como base metodológica ejercicios de anatomía vivencial, respiración, masajes y auto masajes, exploración y uso de niveles, búsqueda de diferentes formas de desplazamiento, estudio de diferentes cualidades de movimiento, velocidades y motores de movimiento, que combinados con el uso de idiokinesis (imágenes), dan lugar a la creación de movimiento propio. La indagación y relación del cuerpo con el espacio y entre cuerpos, son clave para el dinamismo y la composición. La danza contacto, con su tacto, el compartir y repartir el peso, como la improvisación a partir de los elementos anteriormente descritos, explorados individual y grupalmente, son el arsenal desde el que se trabaja.

Estas metodologías, que en la danza se traducen a técnicas de movimiento corporal, tienen como principio desarrollar la escucha personal y grupal, el reconocimiento de la diferencia y el potencial de movimiento individual para, de esta manera, crear un ritmo colectivo y una forma de trabajo grupal, en la que todos participan activamente, de manera horizontal. Para esto, se hace fundamental el cambio de rol constante en las actividades grupales en las que cada participante tiene la oportunidad de experimentar el dar y recibir, dirigir y ser dirigido, entregar y sostener.

Los ejercicios son principalmente heredados del primer taller que se desarrolla en Colombia en el 2007 por las ex bailarinas inglesas, Charlotte Darbyshire y Welly Ónalle, miembros de una compañía inglesa de danza (CandoCo) inclusiva de alto reconocimiento y larga trayectoria en el Reino Unido y el mundo. El educador, bailarín y coreógrafo, Adam Benjamin, también fundamenta dicha práctica integrada en su libro Making an Entrance. Theory and Practice for Disabled and Non-Disabled Dancers (2002).

Durante el 2009 y 2010 se realizan otros talleres con fase de montaje en el Museo Nacional de Colombia y se desarrolla un proyecto que apoya la atención del 
cuerpo-creativo y expresivo, dentro de los procesos de atención psicosocial para víctimas y familiares de mina antipersonal en Villavicencio, a través de Fundación Mi Sangre. Aquí la investigadora es facilitadora de los talleres y asistente de producción de los proyectos desarrollados en esta etapa.

\section{Segunda Etapa: desarrollo de proyectos y consolidación de la compañía}

De forma simultánea, mientras se consolida el proyecto pedagógico de la organización ConCuerpos, también se conforma la primera compañía de danza inclusiva, y se realizan los primeros trabajos coreográficos en el 2009. La compañía se constituye en ese momento por una mujer que usa silla de ruedas, quien tiene experiencia en baile folclórico, un hombre con discapacidad auditiva, con poca experiencia en danza, las tres codirectoras de ConCuerpos de ese entonces y un bailarín de la ciudad de Bogotá. Estos primeros montajes están a cargo de las coreógrafas inglesas invitadas Charlotte Darbyshire y Sarah Storer, creando la pieza Azul y TR9B5 respectivamente. Ambas piezas de cortes diferentes.

La primera pieza Azul, fue creada a partir de pautas de improvisación en las que se explora diferentes cualidades de movimiento a través de la respiración y la danza contacto. Allí se pone en movimiento un mundo ficticio de ensoñaciones, marcado por el mar y el movimiento de los pescados, mezclado con la energía de los bailarines (imagen 6).

Imagen 6. Elenco Azul.

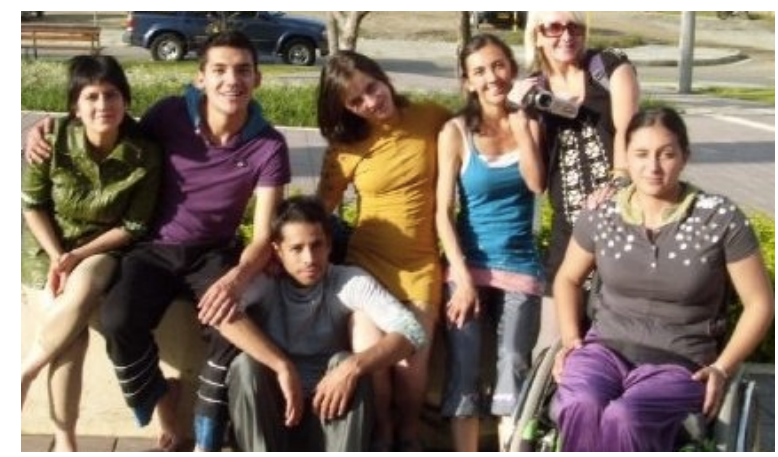

Fuente: Archivo personal

La segunda pieza, TR9B5, es una adaptación de movimiento en el que el grupo se cohesiona llevando cuentas y replicando el material de movimiento que la coreógrafa trae en mente. Allí se pone en juego la idea de la tribu sin importar las diferencias individuales, todos trabajando para un fin común. 
Imagen 7. Dueto TR9B5.

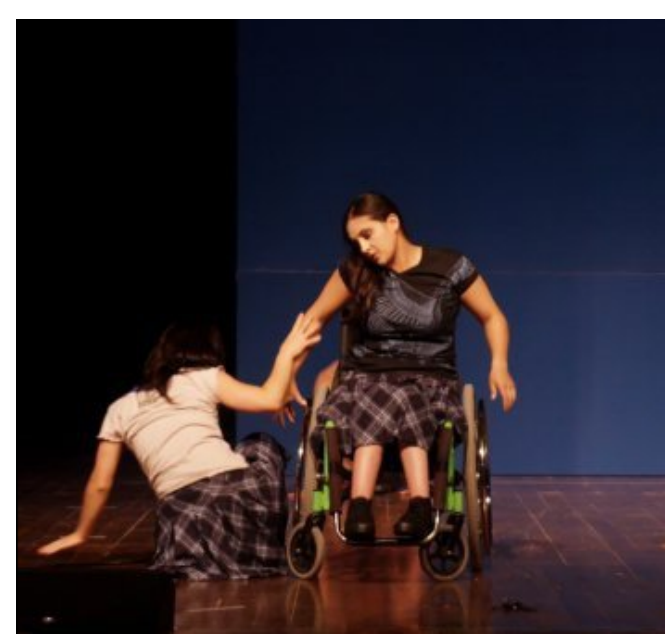

Fuente: Jorge Velázquez

Paralelamente a esta experiencia de creación, hay un tiempo para la creación y los ensayos, el conocimiento a profundidad de un equipo diverso de 7 bailarines, en los que la cotidianidad también permea la práctica dancística. La compañía presenta las obras en diferentes teatros de Bogotá y se presenta en Cartagena, Sincelejo y más adelante en Chile (2010). También se invita a la coreógrafa Natalia Orozco, con quien se desarrolla la pieza Trayecto Pendiente, una obra que tiene tres versiones y se adapta al espacio en el que se desarrolla, como lo son el teatro y los espacios no convencionales.

El área pedagógica se sigue desarrollando, se ofrecen talleres en la fundación Espacio Común y cada vez más se experimentan nuevas formas de comunicación entre los participantes, probando ejercicios propios de la danza contacto y el reléase.

\section{Tercera etapa: clase permanente, segunda compañía, creación colectiva}

Al realizar sus estudios de Maestría, la investigadora toma talleres con la compañía AxIS (2011) (imagen 8) y en la Universidad de Washington (2012), donde a parte de los ejercicios de improvisación y sensibilización, hay un énfasis en la técnica inclusiva. Es decir, el estudio se hace a partir de términos técnicos, por ejemplo, pliés, relevés, suspensiones, estiramientos, caídas, recuperaciones, direcciones, etc. para que cada participante los busque desde su corporalidad y posibilidades de movimiento. Es decir, que un plié, no necesariamente se debe hacer de pie y con las 
Danzando en la diversidad: reflexiones sobre la inclusión y pertinencia de la diversidad en la educación dancística y artística | Carolina Caballero Segura |

piernas, si no que se busca la flexión y dinámica del movimiento en diferentes partes del cuerpo. Así un plié puede hacerse con un brazo sobre una silla de ruedas. Del mismo modo un tendú, jette, etc.

Imagen 8. Taller con AXIS

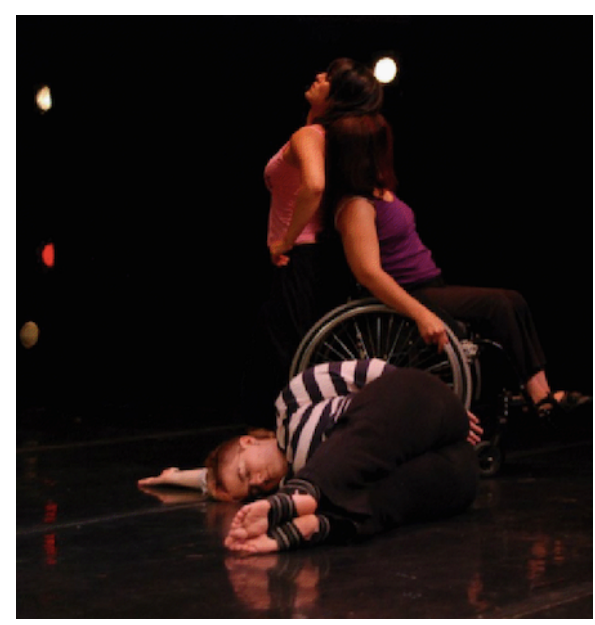

Fuente: Archivo personal

Esta información es transmitida por la investigadora en un taller que se realiza en Bogotá en el teatro Delia Zapata en asocio con el Ministerio de Cultura y ConCuerpos (imagen 9). También se desarrolla un pequeño trabajo coreográfico con alguno de los participantes y con la invitada Karen Daily, quien trabaja de la mano con Alito Alessi en Eugene, el método DanceAbility.

Imagen 9. Taller en Bogotá.

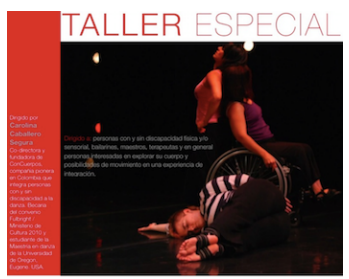

Técnica e improvisación
en Danza Contemporánea Integrada

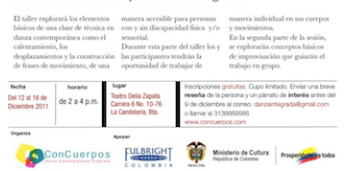

Fuente: Archivo personal 
Daily es una bailarina de 65 años que usa silla de ruedas a causa de una amputación de pierna, por un cáncer en su niñez. La investigadora y tallerista trae previamente pautas de movimiento elaboradas con Karen (imagen 10), que se amplían con la participación y particularidades de los bailarines en Bogotá, quienes en su mayoría son jóvenes sordos y permiten un uso particular de gestos, haciéndolos muy expresivos (imagen 11).

Imagen 10. Karen y Carolina.

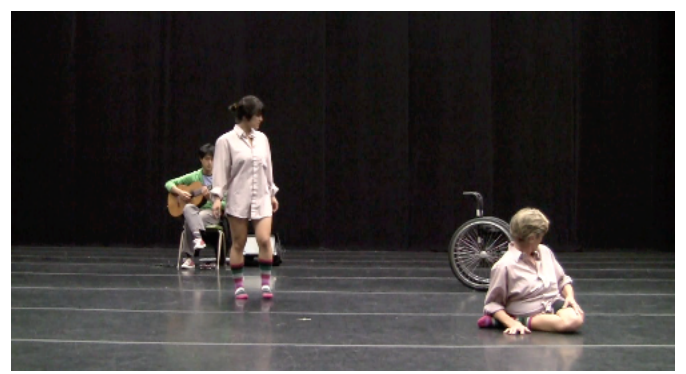

Fuente: Archivo personal

Imagen 11. Exploración en Bogotá.

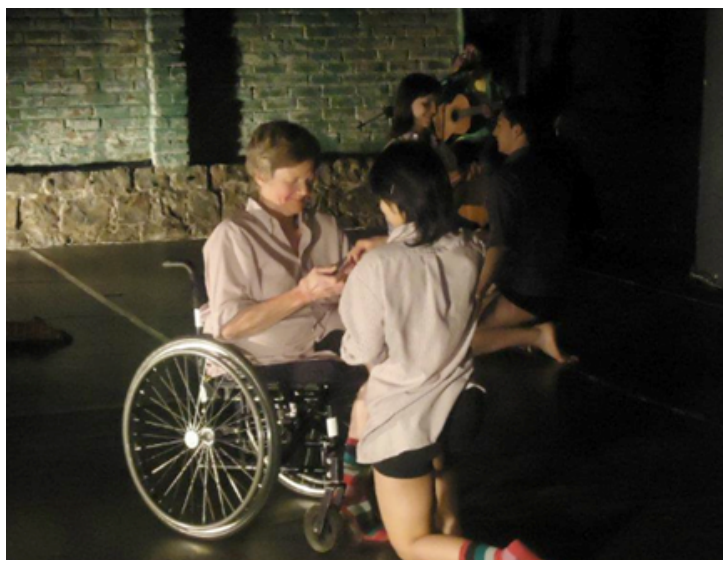

Fuente: Archivo personal

Desde el 2011, ConCuerpos también consolida una clase de danza inclusiva permanente, que se lleva a cabo los días sábados de 2: 00 a 4: 00 pm, en la ciudad de Bogotá. Estas clases han sido facilitadas por Andrea Ochoa en calidad de directora de la organización, y en algunas ocasiones por Carolina Caballero; pero, principalmente, el espacio se ha consolidado como un lugar en que diferentes maestros de Bogotá ponen a prueba sus metodologías volviéndolas incluyentes. 
Danzando en la diversidad: reflexiones sobre la inclusión y pertinencia de la diversidad en la educación dancística y artística | Carolina Caballero Segura |

De esta forma, se ha abierto un espacio para la investigación activa del reto de la inclusión en danza contemporánea. Actualmente la clase continúa y se realizan memorias que están a la espera de ser sistematizadas.

A las clases asisten un grupo de diversas personas, en algunas ocasiones que no se encuentran en ninguna condición de discapacidad, sino que están abiertas a la experiencia; para aprender en la diversidad dado que están interesadas en encontrar su potencial de movimiento, sin importar su edad o que nunca antes lo hayan intentado.

Durante el 2013-2014 se consolida un grupo de aproximadamente 15 personas diversas, que asisten a través de Becas que ConCuerpos facilita a través de los apoyos concertados del Ministerio de Cultura e IDARTES y que hoy en día siguen asistiendo a la clase. También, en el 2014 se consolida la segunda compañía de danza inclusiva ConCuerpos y se crea la primera obra Singular, dirigida por Andrea Ochoa y Carolina Caballero como directoras de ConCuerpos, en una exploración y creación colectiva con la experiencia misma de los integrantes de la compañía.

Esta nueva compañía está conformada por dos mujeres con limitaciones motoras: una mujer que usa silla de ruedas, un hombre sordo, un hombre y tres mujeres sin ninguna discapacidad. Esto es importante, para este segundo momento de la compañía, los integrantes han tenido un previo espacio de formación en la clase permanente y las directoras cuentan con una mayor experiencia artística.

En el proceso de investigación-creación de Singular se desarrolla un lenguaje propio en la compañía, en el que se entretejen las particularidades de cada bailarín al mismo tiempo que se comparten sentires, movimientos y ritmos. El lenguaje de señas juega un papel importante en la creación de material, los coros, solos, duetos y tríos se ponen en escena para recordarnos lo amplio de la experiencia humana (Imagen 12).

Imagen 12. Obra Singular.

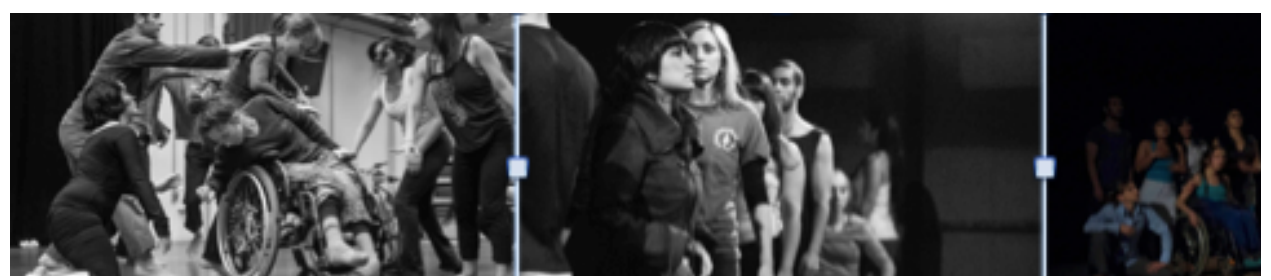

Fuente: Marlén Forero 


\section{Referentes conceptuales en los que se inscribe la danza inclusiva: Aproximaciones a una definición en constante construcción}

La danza contemporánea inclusiva, como su nombre lo indica, tiene sus raíces en la danza contemporánea. Esta última como se consigna en el Plan Nacional de Danza para un País que Baila 2010-2020 del Ministerio de Cultura, hace referencia a un género que "surge como una reacción frente a la rigidez de las formas y el pensamiento de la danza clásica, y como una propuesta que reivindica antes que el dominio técnico la comunicación, la interpretación y la búsqueda del movimiento propio" (p. 53). Esta definición, aunque corta y general, enmarca adecuadamente el marco en el que la danza inclusiva se ubica y encuentra su lugar de desarrollo.

Buscando aproximaciones particulares para la danza inclusiva se puede notar que en el Plan Nacional de Danza, se le enuncia como danza integrada, usada para hacer referencia a la expresión de las personas en situación de discapacidad (p. 14). En un artículo reciente, la docente Martha Ospina (2014) del programa Arte Danzario de la Facultad de Artes ASAB, Universidad Distrital Francisco José de Caldas, denomina a la danza integrada como Nueva Danza para hablar de "la danza de los cuerpos segregados". Ospina la ubica dentro de esas prácticas de la danza que como arte se transforma constantemente, provocando nuevas prácticas y narrativas (p, 155). En el I Encuentro de Danza e Integración Latinoamericana que a la danza inclusiva se le enuncie de diferentes maneras también fue un hecho. Andrea Ochoa, directora actual de ConCuerpos, hablando del Encuentro, lo escribe en su artículo Una Red del Cuidado (2016):

Fuimos convocadas compañías, agrupaciones y personas que venimos trabajando desde la danza con personas con y sin discapacidad desde diferentes aproximaciones y nominaciones. Danza inclusiva, danza integradora, danza de habilidades mixtas, danza integrada, sin límites, con alma... cada grupo apelando a diversos adjetivos pero a un fin común (recuperado el 22 de febrero de 2016 de: http://www. elcuerpoespin.net/revista-digital/una-red-del-cuidado).

¿Cuál es este fin común? ¿Cómo definirla, y darla conocer en nuestro contexto colombiano? En primera instancia, puede decirse que el fin común es reconocer las particularidades de cada persona que se pone en movimiento, escuchar, permitir y crear colectivamente. Lo que se enfatiza en los talleres y encuentros es el reconocimiento de la diferencia de los cuerpos y reivindicar su capacidad y potencial de movimiento, sin importar su condición física, sensorial o cognitiva. Es considerar la diferencia una posibilidad y no una limitación. En la realización de su cartilla, Incluyendo al Cuerpo: Cartilla para el trabajo con niños y niñas diversas a través de la Danza Contemporánea Integrada (2011), el equipo de ConCuerpos apunta a una definición, dejando consignado que la danza integrada, ahora denominada por la misma organización, inclusiva, cobija aquellas prácticas en donde se encuentran 
Danzando en la diversidad: reflexiones sobre la inclusión y pertinencia de la diversidad en la educación dancística y artística

personas con y sin discapacidad y se crea en conjunto, partiendo desde la diferencia y el potencial de movimiento creativo de cada individuo. Esto también dentro del interés de hacer de la danza una práctica más democrática. Importante de esta aproximación es que además, diferencia la danza inclusiva de aquellas prácticas artísticas realizadas sólo por personas en situación de discapacidad (p.13).

Lo que se resalta en esta definición de la danza contemporánea inclusiva es el encuentro y el trabajo colectivo, el reconocimiento y valoración de la diferencia, lo cual da paso a que se hable ya no tanto de cuerpos/sujetos integrados o incluidos dentro de una práctica, sino de diversidad.

Tanto el Plan Nacional de Danza, como el acercamiento que hace la docente Ospina descuidan que para hablar de danza inclusiva debe tenerse en cuenta que si bien hay una valoración de las expresiones de las personas en situación de discapacidad y de los cuerpos que histórica, social y políticamente se han "segregado", sólo hay danza inclusiva cuando se permite un encuentro justo y de igualdad de posibilidades para que tanto personas con y sin discapacidad, puedan explorar sus posibilidades de movimiento y trabajar como un colectivo, expandiendo su capacidad creativa.

En este sentido es que la danza contemporánea, al dar las bases sobre las cuáles se construye un espacio incluyente, permite enfatizar en la construcción de un lenguaje de movimiento propio y diverso que explora la manera cómo podemos relacionarnos y comunicarnos entre personas física, sensorial y cognitivamente diferentes.

En el caso de la educación en danza, este enunciado tiene sus retos pues los cuerpos en condición de discapacidad por lo general no están asociados a una habilidad motora que pueda valorarse para la formación en danza. Por el contrario, más bien podría decirse que, el cuerpo en condición de discapacidad representa la oposición del cuerpo que la danza occidental ha considerado al centro de sus escenarios y manifestaciones, a saber, un cuerpo idealizado en su esbeltez, feminidad, blancura y virtuosidad (Albright, 1997).

La danza contemporánea inclusiva lo que permite, como lo enuncia la misma bailarina y filósofa norteamericana Ann Cooper Albright (1997) es deconstruir la categoría misma del bailarín, bailarina. En la danza inclusiva no se trata de ocultar la discapacidad o de hacerla menos evidente (aunque también puede hacer parte del juego coreográfico desde el que se compone), sino por el contrario, se busca rescatar las posibilidades inherentes de movimiento en los diferentes tipos de cuerpos, buscando salir de las lógicas estéticas de la danza clásica (p. 68). Para los que están inmersos en este campo, se trata de dar valor, belleza, armonía a formas y ritmos, que no han sido considerados como "normales". 
Para que estas consideraciones se propicien cabalmente, la educación actual en sí misma, no sólo en danza sino de cualquier tipo, tiene el reto de la inclusión al centro de sus prácticas, donde la diversidad encuentre su horizontalidad y su valor, como posibilidad de expresión. Es aquí donde puede esclarecerse por qué hoy en día, en particular ConCuerpos, quien hace el esfuerzo de escribir y fundamentar los desarrollos de la práctica, habla de danza inclusiva y no integrada, como bien lo hicieron en un principio.

\section{De la integración a la inclusión: Un cambio desde los aportes de la educación}

Cuando en el 2007 se hizo el primer taller en Colombia que reunió personas con y sin discapacidad alrededor de la danza contemporánea, se convocó al I Taller de Danza Integrada. Como se mencionó anteriormente, ese es el término con el inicialmente se dio a conocer esta nueva práctica en el país. Ese es también el nombre con que ConCuerpos como organización pionera en el país en esta área adopta para constituirse legalmente con su nombre completo ConCuerpos, Danza Contemporánea Integrada en Colombia (Penagos, 2014). Sin embargo, como la organización está también en constante evolución y en diálogo con los avances en los Estudios sobre Discapacidad y Educación Incluyente, recientemente en el 2014 acogió el cambio de danza integrada por inclusiva. Ahora todas sus actividades son designadas bajo esta nueva nominación.

Dicho cambio responde a los recientes aportes que hace la educación cambiando su paradigma en consideración a una educación incluyente. Según los Lineamientos Política de Educación Superior Inclusiva (2013) del Ministerio de Educación Nacional (MEN), en el año 1994 comienza el giro de enfoque. Se considera que el concepto de integración no abarca lo mismo que el de la inclusión. Según estos lineamientos, la integración remite a una perspectiva asumida en los años 80s-90s que se orienta a las personas en situación de discapacidad para atenderlas de manera especial bajo el término necesidades educativas especiales — NEE (p.8).

Este modelo le apuesta a una estructura institucional y curricular diferenciada, que lastimosamente el Ministerio de Educación reporta como fuente de segregación y aislamiento, en el sistema educativo; pues muchas veces se estigmatiza a los estudiantes como personas con necesidades especiales ${ }^{7}$. Aunque, como el mismo artículo del Ministerio de Cultura lo enuncia, no se trata de contraponer los dos términos, más bien se trata de ampliar la perspectiva.

En este sentido, la acción de incluir abarca la integración, mejor aún, va más allá de acciones específicas para atender a un grupo poblacional específico, formulando

7 Ver: http://www.mineducacion.gov.co/1621/article-141881.html. Recuperado el 12 de marzo de 2016. 
Danzando en la diversidad: reflexiones sobre la inclusión y pertinencia de la diversidad en la educación dancística y artística

y brindando unas bases sólidas mediante políticas institucionales, que garantizan la igualdad de oportunidades para todos sus estudiantes. Si bien el término "integrar" sirvió en su momento para dar visibilidad a grupos excluidos del sistema educativo, ya no hace parte del léxico de la educación inclusiva. Esto lleva a precisar que la preocupación de la educación inclusiva es identificar las barreras para el aprendizaje y la participación propias del sistema, buscando que sea el sistema mismo el que se abra y ajuste a las necesidades de los estudiantes y no al revés. Así, la educación inclusiva puede ser entendida como una estrategia central para luchar contra la exclusión social (Lineamientos Política de Educación Superior Inclusiva, 2013, pp. 7-8).

\section{¿Desde dónde se entiende la discapacidad en la danza inclusiva?}

Históricamente han sido varias las miradas y los discursos que han marcado la subjetividad de las personas con alguna discapacidad y por ende, sus cuerpos. La danza inclusiva se ubica dentro del interés por trascender la visión médicobiologicista de la discapacidad, que sitúa y clasifica los cuerpos en términos de enfermedad, normalidad y funcionalidad, como categorías estáticas (Caballero, 2010).

En el 2008, cuando se realiza la investigación Cuerpos IndiVisibles en Movimiento, se evidencia que sobre las personas con discapacidad recae principalmente la mirada médica. Llama la atención que la mayoría de información que se encuentra en la red está relacionada con el fortalecimiento del sector que presta servicios de salud y seguridad social a este grupo poblacional. Adicionalmente, también se constata, como lo denuncia, el abogado y doctor en Derechos Fundamentales, Carlos Parra Dussán, que las personas en situación de discapacidad representan uno de los sectores poblacionales excluidos de nuestra sociedad. El temor, la vergüenza y la minusvalía siguen alimentando los imaginarios de la sociedad sobre estas personas (2004)

Con base en el modelo social de la discapacidad, se entiende que más allá de las limitaciones físicas, cognitivas o sensoriales de una persona, es la sociedad misma la que impone la situación de discapacidad (las barreras) por la forma en que aísla y excluye innecesariamente de la participación plena en la sociedad. Por lo tanto, es posible afirmar que las personas con discapacidad constituyen un grupo oprimido de la sociedad (Barton, 2009).

Por el contrario, la danza inclusiva enfatiza el carácter crítico y relacional de la discapacidad. Es decir, que la discapacidad se define en relación a nociones de normalidad y habilidad que deben ser puestas en cuestión para ser redefinidas y elaboradas conjuntamente entre las personas consideradas como normales y en condición de discapacidad (Hickey-Moody, Crowley, 2012). Citando a la profesora Karen Garzón (2005): 
[la] discapacidad, más que un campo de circulación de saberes, puede constituirse en un campo de relaciones, que no contengan solamente discurso sino práctica social, quizás proponiendo nuevos lenguajes y formas de comunicación no para los sujetos, sino de los sujetos mismos (pp. 5-6).

En este sentido, se considera que la danza inclusiva apunta en esta dirección, brindando un espacio emancipador. La discapacidad se convierte un reto para la creación de movimiento y produce un lenguaje participativo y estético, ya no sólo para las personas en condición de discapacidad, sino común a la diversidad del grupo.

\section{Cuerpo y subjetividad en la danza}

En esta investigación, la emergencia de conocimientos nace desde y a través del cuerpo, recociendo su carácter vivencial, subjetivo y relacional. Por esto, la indagación se ubica más allá de los contornos de la reflexión académica, tomando la experiencia misma de las personas involucradas en los procesos de aprendizaje y creación. La indagación navega entre las reflexiones teóricas, explicativas y las prácticas de quienes están involucrados, para ser consecuentes con el reto que propone Barton (2009), enfrentan los estudios sobre discapacidad, a saber, cumplir con un propósito real y efectivo que apele a un cambio, no sólo actitudinal sino sistémico transformador. Esto conlleva, dice el mismo autor, a pensar críticamente y tener encuentra cuestiones de poder y control en las relaciones que se establecen dentro de los espacios educativos (Barton, 2009). En este caso particular, dónde y cómo se enseña la danza contemporánea y la relación que se establece entre maestro-estudiantes.

\section{Resultados y discusión}

A lo largo del tiempo se evidencia que la danza contemporánea inclusiva es una práctica en constante evolución. La experiencia de ConCuerpos y otras organizaciones y grupos emergentes permite constatar un campo pedagógico y artístico comprometido con la misión de derribar las barreras de participación en la danza contemporánea.

En un primer momento, en el que su cuerpo pedagógico se consolida, poniendo a prueba diferentes metodologías, hoy es posible asistir al repertorio de danza inclusiva de la compañía en escenarios como Danza en la Ciudad (2014), o en Encuentros Latinoamericanos como el de Danza e Integración (2015).

De la primera etapa en la que se realiza el proyecto de investigación Cuerpos IndiVisibles en Movimiento se resalta que la práctica de la danza inclusiva, brinda consciencia al cuerpo expresivo, trascendiendo el cuerpo funcional de las personas con y sin discapacidad, asimismo, que es posible crear otras representaciones para la 
danza contemporánea y que la diferencia puede usarse como un elemento estético en la construcción y desarrollo de material coreográfico. Al respecto:

Es muy chévere darse cuenta de que el cuerpo también puede moverse en otras formas, normalmente uno está acostumbrado a que el cuerpo está ahí y listo, que uno sólo hace las cosas básicas, como ponerse la ropa y arreglarse y ya. Pero con estos ejercicios uno se da cuenta que puede hacer muchas movimientos y pues que tiene un cuerpo (Participante taller Cali, 2008).

Además, se puede constatar que el espacio pedagógico promueve la creatividad y la conexión de las personas sin importar sus diferencias:

Muy agradable, somos un grupo muy compacto, el ejercicio tiene mucha creatividad. En mi vida había escrito mi nombre de tal forma, ipero lo escribí! (Participante taller Cali, 2008).

Puedo llevar mi cuerpo a expresar más, hace que la creatividad se potencie (Participante taller Bogotá, 2008).

Cuando comenzamos a darnos cuenta del otro, hay más conexión, se empieza a componer, hay como unos cuadros muy hermosos, como más estéticos. Al principio cada uno, sin darse cuenta de que estaba con los otros. Luego cuando empezamos a actuar en conjunto se fueron creando imágenes más complejas y bonitas. Por ejemplo, cuando todos estaban quietos y dos en movimiento, ihermoso! (Participante taller Sincelejo, 2008).

Los tres talleres del 2008, junto los posteriores, se consolidaron bajo una metodología que usa la improvisación, la danza contacto y el reléase principalmente para el trabajo inclusivo. Estas prácticas permiten que cada persona explore su propio cuerpo, desde sus propias articulaciones, músculos, huesos y vivencias; que progresivamente se genere un acercamiento al otro y en conjunto se pueda componer, pensando en términos coreográficos.

El reto de la inclusión en la práctica pone el acento en la comunicación, ¿cómo se crean espacios en los que tanto una persona ciega, como una sorda, entiendan un ejercicio, aunque la vía de la comunicación sea diferente?, uno por vía oral y el otro visual, o ¿cómo se realizan desplazamientos incluyendo tanto a los que caminan, como los que usan sillas de rueda u otros apoyos? Esto pone en evidencia la claridad en el lenguaje, el uso de términos incluyentes y la creación de situaciones, así como la importancia del aprendizaje de la lengua de señas. En esa medida, puede decirse que la danza inclusiva hace hincapié no sólo en lo que se hace, aunque por supuesto hay una investigación constante, sino también en la coherencia en el quehacer y en la manera en cómo se hace de acuerdo a las posibilidades de quienes participan en el grupo. Cuando el facilitador usa su rol para incentivar y promover procesos de acercamiento, cuando no se posiciona desde un lugar de saber, si no de curiosidad y asombro, cuando hace que todos y todas se sientan igualmente valorados, cuando 
propicia el cuidado y el respeto y la colaboración, cuando suelta su normalidad y se sumerge en la complejidad y diversidad de los grupos, hace surgir los ambientes de enseñanza incluyentes. Es por esto que ningún grupo es igual a otro y que en las clases y procesos de danza inclusiva se cuenta con un intérprete y se promueve el aprendizaje y uso de la lengua de señas.

Con el tiempo, en la segunda etapa se hace claro que cada persona es un ejemplo de diversidad, no sólo porque en los espacios pedagógicos incluyen diferentes tipos de discapacidad, sino porque asisten personas de diferentes edades, clases sociales, personalidades, etc. También porque cada individuo tiene una percepción particular sobre su sí mismo, así como formas diferentes y particulares de aproximarse al movimiento y su cuerpo.

Lo que demuestran los años de talleres y clases es que la danza inclusiva busca explorar el cuerpo y el movimiento en una forma que extienda posibilidades y conexiones, con el sí mismo, con los otros y con el espacio, de acuerdo con cada individuo. La práctica está pensada para trabajar con las personas y no exclusivamente con la discapacidad.

En esa medida, se ha hecho posible deconstruir una noción de danza, con formas fijas, definidas y codificadas. Se acentúa el gesto y con ello se propone una danza nutrida por la improvisación, la economía del movimiento, la belleza del caos, el contacto entre cuerpos y el sentido físico del movimiento.

Al comienzo del proyecto, la observación de que las personas en condición de discapacidad son tratadas con un alto grado de dependencia fue imponente. Por ejemplo, se evidenció con frecuencia que se habla de ellos, por sus familiares, acompañantes o terapeutas como si no estuvieran presentes, o no pudieran decidir por sí mismos. Todo se les hace, se les dice, se opina por ellos; pocas veces se les pregunta directamente cómo se sienten, qué quieren, cómo quieren.

En este sentido, el trabajo de ConCuerpos también rompe con una jerarquía implícita en los cuerpos. En los ejercicios siempre hay un cambio de rol y en algunos casos se evidencia que algunos de los terapeutas se ven confrontados al verse horizontalmente con su "paciente". En los procesos pedagógicos es frecuente encontrar que algunas personas con discapacidad tienen un mayor reconocimiento de su corporalidad, de sus posibilidades de movimiento, mostrando mayor dedicación, facilidad y agilidad en el trabajo, que sus mismos terapeutas. Empodera observar cómo en algunas oportunidades ellos son quienes lideran el trabajo que se hace en conjunto, por parejas o tríos. También es importante que dentro de la experiencia de la danza inclusiva emergen procesos que no son estrictamente artísticos, sino que hacen parte del proceso social que se potencializa durante el encuentro y trabajo en conjunto. Las personas realmente abren sus posibilidades de movimiento, lo cual es 
Danzando en la diversidad: reflexiones sobre la inclusión y pertinencia de la diversidad en la educación dancística y artística

uno de los objetivos principales de los talleres y las clases, pero además, se plantean múltiples reflexiones sobre qué es la discapacidad, capacidad, reivindicación, dignidad, lo diferente, lo compartido, cuál es la concepción de danza, del cuerpo, de la belleza, etc.

Por su puesto, estéticamente, el trabajo de ConCuerpos también aporta, pues visibiliza una propuesta que construye un lenguaje contemporáneo dentro de la danza, menos esquematizado, más orgánico a los cuerpos, y por lo tanto, con más retos de comunicación. En tanto que el proyecto incluye personas que normalmente han sido excluidas de la participación en danza contemporánea u otras actividades artísticas, al pedirles que contribuyan con su creatividad y originalidad se abre un espectro vasto de posibilidades. Entonces no sólo se amplían las posibilidades de composición, sino que se crean más preguntas, nuevos cuestionamientos aportando a nuevas miradas artísticas. La obra Singular por ejemplo responde a la pregunta ¿qué es normal? De manera interdisciplinaria y tomando la subjetividad de cada uno de los integrantes de la compañía, la obra muestra que puede ser normal rodar por las calles, no escuchar, hablar con lenguaje de señas o ser homosexual. El movimiento es una exploración de lo más íntimo de los bailarines, sus gustos, sus encantos, sus extrañezas, lo que los hace un grupo diverso y a la vez les permite convivir bajo la misma finalidad creativa, dentro de una atmósfera de respeto, cariño y preocupación de los unos por los otros.

Lo que está en juego es entonces la expresión de la humanidad a través del movimiento. Concibiendo al movimiento como algo siempre novedoso y en constante expansión, contrario, como se ha mencionado, a la repetición de formas ya establecidas.

En la pedagogía se vivencia aún más la idea de respeto por el proceso de cada quien, teniendo en cuenta sus tiempos específicos, las necesidades y ayudas para sus movimientos. Sin embargo, también hay un nivel de exigencia incluyendo a la discapacidad por igual. En este sentido, se pide una claridad en la acción, un esfuerzo por definir recorridos, por aprender material de movimiento; una limpieza general del movimiento. Lo cual exige entrenamiento constante, en la que el bailarín está buscando siempre expandir su repertorio y superándose así mismo física y emocionalmente.

Lo que se espera es que las personas puedan empezar a moverse desde su propio cuerpo, desde una perspectiva interna, más que desde la imagen externa de sí mismos, juzgando o predeterminando qué es lo que debería hacerse. Es por esto que se hace énfasis en el contacto, en el trabajo con los ojos cerrados, en el no copiar a los o las compañeras, sino de interpretar, para de esta forma despertar el reconocimiento interno del cuerpo y desde allí realizar el trabajo de composición. 


\section{Conclusiones}

A través del tiempo se plantan semillas. Crecen los espacios. Se plantea la reflexión y se refina la comunicación. Cada vez hay menos división, se hace arte con la vida, con su pluralidad. En los procesos de danza contemporánea inclusiva que plantea ConCuerpos, esa línea divisoria entre las personas con y sin discapacidad se hace cada vez más delgada. Los términos comienzan a cambiar. Ya todos tienen un nombre, no el de una categoría que le marca su subjetividad, sino un nombre propio y con él una forma particular de estar en el mundo. Los apoyos se intercambian y los aprendizajes se potencian. Las risas van y vienen.

A través de los procesos pedagógicos y artísticos, es claro observar cómo los cuerpos y movimientos de los participantes reflejan la forma como éstos establecen su comunicación con el mundo. En los talleres y obras, sus cuerpos crecen, reivindican su presencia, se hacen más grandes y propositivos, Ilenan los espacios, transmiten nuevas miradas y significados. Cada vez más, crecen los participantes, el repertorio de las obras, los profesionales interesados en la construcción de espacios pedagógicos horizontales y plurales. Se sensibilizan públicos y con esto la discusión se abre al ámbito público. Si es posible bailar y respetar las diferencias corporales y subjetivas, es posible reconocerse como territorios de paz, plurales e inclusivos.

Para los futuros maestros, está en sus manos crear ambientes en los que las barreras de participación sean cada vez menos, en los que las formas de comunicación sean múltiples. Así en su encuentro con los danzantes, su tarea no será la de imponer, sino la de permitir y propiciar autoconocimiento; se espera que se deje permear, sorprender y potenciar su creatividad y la de quien los acompaña.

\section{Agradecimientos}

Al profesor Carlos Vásquez por su escucha, paciencia y apoyo en la organización de ideas y a ConCuerpos por permitirme un espacio para la reflexión y el movimiento. 
Danzando en la diversidad: reflexiones sobre la inclusión y pertinencia de la diversidad en la educación dancística y artística | Carolina Caballero Segura |

\section{Referencias}

Barton L. (2009). Estudios sobre Discapacidad y la Búsqueda por la Inclusividad. Observaciones. Revista de Educación, 349, pp. 137-152.

Benjamin, A. (2002). Making an Entrance. London: Routledge.

Caballero, C. (2010). El movimiento diverso de los cuerpos. Cuerpos Entre Líneas. Publicación de la OFB.

Citro, S. (Coord.). (2011). Cuerpos plurales: antropología de y desde los cuerpos. Buenos Aires: Biblos.

Citro, S. y Aschieri, P. (Coord.). (2012). Cuerpos en movimiento: antropología de y desde las danzas. Buenos Aires: Biblos.

Hickey-Moody A. y Crowley, V. (2012). Disability Matters. New York: Routledge.

Horton, S. y Hantein, P. (1999). Researching Dance. Evolving Modes of Inquiry. Pittsburg: University of Pittsburg Press.

Penagos, A. (2014). ConCuerpos danza integrada. Revista iLetrada. No 22. Recuperado en marzo 2015 de: http://letrada.co/post/paraguero/181/concuerpos-danza-integrada

Ochoa, A. (2016). Una red del cuidado. El CuerpoSpin. La revista de danza y artes escénicas. Recuperado de: http://www.elcuerpoespin.net/revista-digital/una-red-del-cuidado.

Vigo, B. y Soriano, J. (Coord.). (2013). Educación Inclusiva. Desafíos y respuestas creativas. Zaragosa.

Recibido: 10 de junio 2015

Aceptado: 28 de agosto 2015

Cómo citar: Caballero, C. (2016). Danzando en la diversidad:

reflexiones sobre la inclusión y pertinencia de la diversidad en la educación dancística y artística. Praxis Pedagógica, 18, 27-51 